\title{
Regulatory Challenges of Nanofood Labelling
}

\author{
Nor Akhmal Hasmin ${ }^{1}$, Zinatul Ashiqin Zainol ${ }^{2}$, Rahmah Ismail ${ }^{2}$ \& Anida Mahmood ${ }^{3}$ \\ ${ }^{1}$ Centre of Foundation Studies, Universiti Teknologi MARA, Cawangan Selangor, Kampus Dengkil, Dengkil, \\ Selangor, Malaysia \\ ${ }^{2}$ Faculty of Law, Universiti Kebangsaan Malaysia, Bangi, Selangor, Malaysia \\ ${ }^{3}$ Faculty of Law, Universiti Teknologi MARA, Shah Alam, Selangor, Malaysia \\ Correspondence: Nor Akhmal Hasmin, Centre of Foundation Studies, Universiti Teknologi MARA, Cawangan \\ Selangor, Kampus Dengkil, 43800 Dengkil, Selangor, Malaysia. Tel: 60-1-9207-0264. E-mail: \\ norakhma15559@uitm.edu.my
}

$\begin{array}{lrr}\text { Received: April 10, } 2020 & \text { Accepted: April 30, } 2020 \quad \text { Online Published: May 30, } 2020 \\ \text { doi:10.5539/jpl.v13n2p241 } & \text { URL: https://doi.org/10.5539/jpl.v13n2p241 }\end{array}$

\begin{abstract}
This article examines four regulatory challenges of nanofood labelling from the domestic context namely, scientific uncertainties shrouded the tiny particles, absence of a harmonised legal definition, detection issue of nanomaterials in a final product, and complexity in implementation and enforcement. This article also offers discussion on the possible ways to overcome these challenges. It establishes that mandatory labelling can be implemented within Malaysia food regulatory framework. It can be done by narrowing the labelling requirement to food with engineered nanomaterials (ENMs), adopting the precautionary principle, clarify the legal definition of ENMs for food law, robust techniques to detect, measure, and characterize diverse ENMs in food matrices, and strengthen the enforcement institutions. Importantly, this study hopes to significantly contribute to improving the legal provisions on food information system for a product of emerging technology such as nanofood by pushing forward the legal requirement for nanofood labelling.
\end{abstract}

Keywords: engineered nanomaterials, mandatory labelling, nanofood, regulatory challenges

\section{Introduction}

The proliferation of emerging technologies is no longer the sole interest of scientists. The regulatory authorities are also on high alert on every scientific and technological discovery (Moses, 2013). They are interested in examining the legal implications of the emerging technologies towards the society particularly analysing the sufficiency of the regulatory framework to regulate the activity or product of the emerging technologies (Brownsword \& Goodwin, 2012). Introducing new regulatory measures governing emerging technologies challenged the regulatory authorities in deciding on the appropriate regulatory measures when they do not have the full grasp of knowledge of intended or unintended adverse impacts (Reins, 2019).

Nanotechnology is a prime example of emerging technology that could produce both positive and negative impacts on society. The applications of nanotechnology in the agriculture and food industry are pervasive from agriculture to food processing, food packaging and food storage as the tiny properties can be tailored for the beneficial property (King et al., 2018). Unfortunately, there is also a rising concern among consumers over the potential safety and health effects. The in vivo, in vitro and in silico studies reported on oral exposure of ENMs in food may cause the indirect source of food contamination and potentially give adverse effects on the gastrointestinal tract (GIT) (Martirosyan \& Schneider, 2014). For that matter, the use of nanotechnology should be balanced and carefully monitored by a regulatory framework. Despite the concerns, nanofood has not being mandated for labelling requirement in Malaysia. The label is not to suggest that nanofood is dangerous, and consumers should avoid it. The objective of labelling is to enable consumers' informed choice on food that they consume, enhance information transparency and increase food traceability in the market.

Likewise, the labelling of nanofood is not yet recognised as international food labelling standard by international food standardizing body, Codex Alimentarius. There is no consensus between Codex's members on this issue. The European Union is for the labelling and the only jurisdiction that imposed mandatory labelling (Ismail et al., 2019). The mandatory labelling is prescribed by Regulation (EU) 1169/2011 on consumers food information, aim to increase information transparency, nanofood traceability and as a precautionary measure to prevent and 
minimize the safety and health risks (Salvi, 2015). Meanwhile, the United States is against the idea. According to the United States Food and Drug Administration (FDA), it is impossible to impose mandatory labelling on nanotechnology products since there are few unresolved issues on regulating the technology. Manufacturers are advised not to label their products as it could mislead consumers (Food and Drug Administration, 2007).

\section{Regulatory Challenges for Nanofood Labelling}

The implementation of mandatory labelling for nanofood is a challenging and treacherous regulatory action. It involves a different setting, variety of substances and products that traverse the domestic regulatory jurisdiction and dictate the agenda of different domestic agencies. This is what the articles intends to discuss, which is on the regulatory challenges if mandatory labelling for nanofood were to be introduced within the Malaysia food regulatory framework.

\subsection{Scientific Uncertainties Shrouded the Tiny Particles}

The primary concern is how to regulate a product or activity that is shrouded by scientific uncertainty. Nanotechnology is synonym with uncertainty because intended and unintended effects are not fully known, and such uncertainty includes the nature of nanomaterials and nature of risks itself. Nanomaterials used in the agricultural and food industry is classified into three categories, naturally occurring, incidentally occurring and manufactured or engineered nanomaterials (ENMs) (Roger, 2016). Which types of nanomaterials should be regulated? Whether all food products contain either category of nanomaterials should be labelled?

Besides, it is also uncertain whether nanomaterial that currently used in the food industry should be treated as new or existing materials. The FDA invoked the position that nanomaterials used in the agricultural and food industry are not new materials because they are just smaller version of bulk materials that have been widely used for so long and deemed to be safe (Gray, 2012). For instance, silicon dioxide and titanium dioxide can be found in the form of nanomaterials and bulk materials whereby the bulk materials have already been in the market for so long. If nanomaterial is not new materials but just a smaller version of bulk counterparts, then labelling is irrelevant.

In addition, the extent, probability, and magnitude of risks towards safety and health are scientifically uncertain (Snir, 2014). Even among scientific communities, the risks of nanomaterial are still much debated. The FDA strongly hold that not all nanomaterials in food are harmful (Food and Drug Administration, 2007). Whereas for Friends of the Earth, the tiny materials come with big risks, and an increasingly large volume of peer-reviewed evidence demonstrate that ENMs may harm human safety and health (Friends of the Earth, 2014).

Enacting regulatory measures for scientific activities that pose safety and health risks commonly revolved around relatively mature industries where the adverse effects are certain and widely acknowledge (Roca et al., 2017) such as regulation on asbestos or nuclear power. But then, how can regulatory authority control and monitor activity or product that is not definitively proven to be harmful or what can be considered as the reasonable concern of ENMs that requires such product to be labelled?.

\subsection{Definitional Issue of Nanomaterials}

The imposition of regulatory measure required a harmonised legal definition of nanomaterials to facilitate the uniform identification on whether a food is classified as nanofood. Defining nanomaterials is not easy, and the central challenge is to determine the scope of definition (Dana, 2012). The definition must be broad enough to include materials that pose a potential risk and risk-creating properties. Still, it cannot be too broad as to include unknown materials which make it difficult for the regulatory measure to be implemented.

As for Malaysia, the applications of nanotechnology in various industries is not yet governed by any legislative acts. Consequently, the legal definition of nanomaterials is unavailable. The nanotechnology standard in Malaysia is based on ISO/TC 229: Nanotechnologies, and it is used as the reference for all other regulatory and research activities (Letchumi, 2013). Arguably, it shall include activities in the agricultural and food industry. The scope of the ISO standard is to understand and control of matter and processes at the nanoscale, typically, but not exclusively, below 100 nanometres in one or more dimensions where the onset of size-dependent phenomena usually enables novel applications (International Standard Organization, 2005)

According to ISO nanomaterial is defined as the material with any external dimension in the nanoscale (length range approximately from $1 \mathrm{~nm}$ to $100 \mathrm{~nm}$ ) or having internal structure or surface structure in the nanoscale and this is inclusive of nano-object (second and third external dimensions are orthogonal to the first dimension and to each other) and nanostructured material (International Standard Organization, 2019). 


\subsection{Detection of Nanomaterials in the Final Product}

Labelling is only possible if the presence of ENMs in the final food products can be conclusively identified and verified (Stokes, 2012). The verification is to guarantee the accuracy of the information and to avoid the misuse of nano label for marketing or promotional purpose. What needs to be proven is the final product contain ENMs, or product feature is enhance through nanotechnology. The characteristic of ENMs in the final product must correspond with the legal definition of ENMs prescribed by labelling legislation. According to FDA, nanotechnology product should not be labelled because detection of nanomaterials in the final product is challenging due to the lack of detection analysis to verify that a product contains ENMs (Food and Drug Administration, 2007). The difficulties exist because of several factors such as the amount of ENMs intended to be incorporated in foods is at a low level, unintended migration from food packaging to food matrices, bulk materials intentionally added to foods may unintentionally include some fraction with nanoparticles, and complexity or variability of the food matrices such as dry food, partially hydrated food, powders, liquid and fresh produces (Singh et al., 2014).

\subsection{Complexity in Implementation and Enforcement}

When the labelling is mandatory, it will challenge the ability of the food authority to implement and enforce the legal mandate. The challenge shall include the ability to provide necessary facilities such as laboratories equipped with apparatus for detection and verification analysis. The food authority also must ensure compliance from local and foreign manufacturers or distributors. The enforcement of mandatory labelling not only affected the domestic scene, but it also requires international cooperation and standardization, because nanofood routinely cross borders through trading activities. Unfortunately, the request for international cooperation would be difficult because there is no consensus by the international community on the labelling of nanofood and as mentioned earlier labelling of nanofood is not recognised by Codex Alimentarius. Besides that, nanofood enters the market without pre-market review or approval, which make it difficult for the food authority to monitor compliance.

The complexity of implementation also involves the possibility that mandatory labelling could slow down or stifle the advancement of nanotechnology not only in the agriculture and food industry but other industry as well. There is concern that public perceived nano label as a form of warning and considers food with nano label is riskier than food without nano label (Chuah et al., 2018). Besides that, the nano label will not be insignificant if consumers are not aware of it and fails to acknowledge the existence and importance of the nano label.

\section{Findings and Discussion}

The descriptions of challenges listed above should not be the ground to push aside the effort to increase the transparency of information on nanofood. This article believed there are ways to overcome these challenges, and the description of possible solutions are not intended to be the comprehensive descriptions of how the authorities should respond to regulatory labelling of nanofood. But it is to inhabit the idea that despite the four challenges, mandatory labelling is possible and could be implemented.

\subsection{Regulate the Uncertainties}

This article believed that only food with intentionally added ENMs should be labelled. While food with naturally or incidentally occurring materials should be excluded from the labelling requirement. The naturally exist nanomaterials such as in milk, mayonnaise, the structure of muscle in meats, fish and carbohydrate-based food caramels, viz. bread, jaggery is proven to be harmless to safety and health (Rogers, 2016). It is the ENMs that intentionally added to food products or food packaging pose higher risks to human health (Gray, 2012).

Besides that, it is scientifically certain that ENMs should not receive similar treatment with bulk materials as it is scientifically proven ENMs is a new material with entirely novel properties distinct than the bulk materials (Schwirn et al., 2014; Friends of the Earth, 2014). For instance, the bulk form of silicon dioxide (food additives) that commonly added to food or food supplement is well understood and appropriately regulated as an authorized food additive. However, nano silicon dioxide has entirely different physicochemical characteristics than bulk material such as tiny size distribution, shape, surface area and roughness which influence the toxic manifestation of nanomaterials. Even the European Food Safety Authority (EFSA) unable to give the nano silicon dioxide the safety all-clear (EFSA, 2018).

Next is the scientific uncertainty of risks associated with nanomaterials. Admittedly, the nature of risk is still surrounded with uncertain. However, it does not mean that nanofood should be left unregulated while the public takes up potential health risks. A precautionary measure against the uncertain or unanticipated risk must be available, to enable the public to act cautiously around nanofood. Currently, the food regulatory framework in 
Malaysia is governed by the risk-based regulation as required by Codex Alimentarius (Food Safety and Quality Division, 2004). The risk-based regulation refers to a regulatory strategy that characterised the risk by using technical assessment or risk analysis before the introduction of any regulatory measure. This approach is adopted to regulate a situation with the probability of occurrence, and the extent of harm is relatively well known (Klinke $\&$ Renn, 2002). The regulatory priority is directed toward the activity with high-risk where it most needed. The regulation for nuclear energy, chemical facilities, nuclear, biological and chemical weapon or known infectious diseases are based on this approach. If scientific information is uncertain, the risk will be left with minimum control or enter the regulatory vacuum because authority is unlikely to adopt any regulatory measure for something that is invalidated (Rothstein, 2006).

The food authority can regulate the uncertainties of nanotechnology by shifting its regulatory approach, adopting the approach that acknowledges the scientific uncertainty or unforeseen effect of emerging technology. Perhaps, the recommendation provided in the Dakar Statement on Manufactured Nanomaterials (IFCS/FORUM-VI/07w) 2008 can be adopted. It was recommended that government and industry apply the precautionary approach as one of the general principles in managing risks of nanotechnology (Intergovernmental Forum on Chemical Safety, 2008). The risk-based regulation is irrelevant for nanotechnology, and it must be replaced with precautionary-based regulation, a regulatory approach derived from the precautionary principle.

The precautionary principle is a long-standing legal principle, refers to a regulatory approach that allows the regulatory authority to take pre-emptive action or precautionary measure in protecting the society by anticipating the potential hazard before full scientific certainty (Todt, \& J. L. Luján, 2014). The principle has been adopted to regulate activities or products of new and emerging technology which is characterised with unknown risk or lack of scientific certainty caused by insufficient scientific information. The intervention from regulatory authority is permitted even without evidence of serious and irreparable damage or having to wait for threats of harm to materialise. It is sufficient to prove potential adverse effects or threat of harm from the use of a product (Hansson, 2017) using scientific evidence (Sachs, 2011).

If there is sufficient data indicates the potential adverse effects, regulatory intervention is justified, particularly in the area of high public concern such as food safety. Laboratories studies demonstrating the adverse effects of ENMs toward health and safety are sufficient to cause concern and justify the decision to introduce mandatory labelling. Therefore, instead of relying solely on the risk-based regulation, the food safety authority in Malaysia must shift its regulatory approach to precautionary-based regulation. The precautionary principle has been legally recognized in Malaysia and expressly embedded in the Biosafety act 2007 [Act 678]. The Biosafety Act could provide a valuable guideline on how to apply the principle towards nanofood.

\subsection{One Definition Will Not Fit All}

Standardize legal definition of nanomaterials is in critical need as it forms the basis for regulatory labelling (Aschberger, et al., 2014). Admittedly, it is impossible to have a standardized definition of nanomaterials, especially between countries as it requires collective effort and consensus. The rapidly growing applications of nanotechnology in the agricultural and food industry are not yet being harmonised under any international regulatory frameworks. Besides, the definition of nanomaterials between industries should not be generalized as physico-chemical properties of nanomaterials used by one industry could be distinct from other industry. The concept of one size fits all may not be relevant for nanomaterials, and the definition should be based on case to case basis (International Standard Organization, 2019). The legal definition of nanomaterials for labelling of nanofood must fit the characters of nanomaterials that commonly available in the agricultural and food industry.

Reference can be made to the legal position in the European Union. In ensuring the consistency and coherency, only a single legal definition of nanomaterials adopted in the area of food law as defined under Regulation (EU) 2015/2283 on novel food. Article 3 (2) (f) Regulation (EU) 2015/2283 on novel food define ENMs as:

“...any intentionally produced material that has one or more dimensions of the order of $100 \mathrm{~nm}$ or less or that is composed of discrete functional parts, either internally or at the surface, many of which have one or more dimensions of the order of $100 \mathrm{~nm}$ or less, including structures, agglomerates or aggregates, which may have a size above the order of $100 \mathrm{~nm}$ but retain properties that are characteristic of the nanoscale.

Properties that are characteristic of the nanoscale include:

(i) those related to the large specific surface area of the materials considered; and/or

(ii) specific physico-chemical properties that are different from those of the non-nanoform of the same material."

As explained in previous paragraphs, only food with ENMs should be labelled due to safety and health concern. 
Therefore, the legal definition of nanomaterials for labelling purpose must clearly indicate that nanomaterial is only referred to ENMs and not naturally or incidentally occurring nanomaterials. For example, the European Union definition of nanomaterial only confines to ENMs. It is suggested that to ensure the successful implementation of the mandatory labelling, there must be a modification on the current definition of nanomaterials, and it should not only focus on size limit and dimension. The definition must be relevant with the application of nanotechnology in the agriculture and food industry, where the element of distribution, properties, dissolution and nature of the nanomaterials (natural, incidental or engineered) must be taken into consideration. The definition of nanomaterials for food law in the European Union under Regulation (EU) 2015/2283 could be used as a point of reference to formulate a legal definition of nanomaterials for domestic application.

This article believes that it is possible to have a domestically harmonised legal definition applies only to the food industry or food laws. The relevant food laws either Food Act 1983 or Food Regulations 1985 can be amended to incorporate the legal definition of nanomaterials meant for the food industry, including food labelling.

\subsection{The Ability to Detect the Tiny Particles}

The available literature listed and described several techniques to analyse the presence of ENMs in food products. According to Contado (2015), several techniques available to measure the size, distributions of ENMs, surface area and its composition. For instance, the Electron Microscopy techniques are still the most popular among the sizing methods, followed by Dynamic Light Scattering (DLS) and X-ray Diffraction (XRD). Atomic Absorption Spectroscopy (AAS) and Inductive Couple Plasma Mass Spectrometry (ICP-MS) is used to identify chemical composition. Whereas, scanning electron microscopy (SEM) and transmission electron microscopy (TEM) is the most widely used technique to measure the size of particles and visualize their morphology.

The scientific committee of the European Food Safety Authority (EFSA) issued a guideline on possible technique to determine physicochemical parameters of ENMs. EFSA Guidance on the Risk Assessment of the Application of Nanoscience and Nanotechnologies in the Food and Feed Chain 2011, laid down the requirement for identification, detection and characterisation of ENMs prior to use and in food/feed applications. Detection can be made using existing guidelines such as IUPAC (Harmonized guidelines for single-laboratory validation of methods of analysis, Pure and Applied Chemistry 74 (5), 835 - 855 (2002)) or Commission Decision 2002/657/EC or to follow any latest method performance test guideline (European Food Safety Authority, 2011). The European Commission also ran a special project known as NANOLYSE (Nanoparticles in Food: Analytical methods for detection and characterisation) from January 2010 until September 2013, aim to develop validated methods and reference materials for analysing nanoparticles across a range of food and beverages (European Commission, n.d).

The food authority in Malaysia may emulate the practice in the European Union by developing a standard operating procedure (SOP) for detection and characterisation of ENMs in food products. The SOP is to bridging the gap from the legislative requirement to enforcement. It guides the food industry, laboratories, and enforcement authority on steps or methods involves. It is suggested that the SOP must consider the standardise methods for quantification and characterisation of ENMs in food matrices such as for powdered food, dry food, beverages, fresh produce, or to identify migration of ENMs from food contact materials to food matrices and list of pertinent classes of ENMs in food products. The well-established procedure will result in the uniformity and accuracy of the analysis and ensure effective enforcement.

It is pertinent to mention that the France General Directorate for Competition Policy, Consumer Affairs and Fraud Control (DGCCF) has tested 114 consumers' good across France for the presence of titanium dioxide nanoparticles. The presence of nanoparticles found in confectionery, sauces, spices and cake toppings and decorations (Michail, 2017). Meanwhile, the French consumer association UFC-Que Choisir, tested 20 consumer goods and seven food products were contained a significant proportion of undeclared nanoparticles in their products (Michail, 2018). It is also important to highlight the voluntary certification program for nanotechnology product in several countries such as Malaysia, Taiwan, Iran and Thailand. A product will be certified as nanotechnology product after a rigorous detection and verification analysis done by certification agency to prove the presence of nanomaterials in the final product or the incorporation of nanotechnology in the manufacturing process by certification (Asia Nano Forum, 2018).

This article unable to suggest which detection and characterisation analysis is the most appropriate or how detection should be carried out as this article only focuses on the legal issue. Nevertheless, these examples illustrate that with technological advancement, it is possible to detect and verify the presence of ENMs in the final product. The remaining issue is whether the detection analysis can be routinely applied over a huge volume of food products and to what extent the test is accurate because of the complex characterisation on nanomaterials, 
and the food itself is a complex and intricate material.

\subsection{Comprehensive Institutional Dimension in Governance of Nanotechnology}

The Food Safety and Quality Division (FSQD) under the Ministry of Health (MOH) is the governmental agency that responsible for the enforcement of food labelling requirement as prescribed under the Food Act 1983 and Food Regulations 1985. Arguably, if mandatory labelling for nanofood is implemented, the FSQD is the agency responsible for the implementation and enforcement. As nanofood is derived from nanotechnology, collaboration from other institution deems necessary, particularly with nanotechnology research centres.

In Malaysia, there is a strong commitment by the government in R\&D of nanotechnology. The commitment and dedication can be seen through various efforts undertaken by the government either in the form of formulation of policies or establishment of institutions. The first national policy on nanotechnology was launched in 2006 known as Malaysian Nanotechnology Initiatives, aim to lead nanotechnology as sustainable national development of science, technology, industry and new growth engines for the country's New Economic Model (NEM) (Hamdan, 2014). In 2009, the National Nanotechnology Directorate was established to coordinates and accelerate various nanotechnology R\&D activities, and public awareness program encourages invention, innovation and technology (Karim \& Munir, 2015). A year later, two nanotechnology centres were formed, identified as NanoMalaysia Centers of Excellence and Nano Malaysia Berhad (NMB) to manoeuvre the economics of nanotechnology industry in Malaysia. These organisations are under the auspicious of the Ministry of Science, Technology and Innovation (MOSTI) (Hamdan, 2014).

As for research infrastructure, Malaysia has a well-equipped nanoscience or nanotechnology research centres, able to provide meaningful contributions not only for $\mathrm{R} \& \mathrm{D}$ but also assisting regulatory authority to solve the regulatory issues by providing relevant scientific information. Currently, there are seven public universities (University of Malaya, Universiti Sains Malaysia, Universiti Kebangsaan Malaysia, Universiti Teknologi MARA, Universiti Putra Malaysia, Universiti Malaysia Perlis and Universiti Teknologi Malaysia) and four private universities (Universiti Teknologi Petronas, Nottingham University Malaysia Campus, University Malaysia of Computer Science \& Engineering and Multi Media University) with specialised nano research centres. Besides, SIRIM Berhad under the Advanced Materials Research Centre (AMREC) also has established the Industrial Nanotechnology Research Center (Karim \& Munir, 2015).

In addition, the food authority may engage with private laboratories that offer services for nanomaterials detection analysis. The private laboratories must be certified by the Ministry of Health (MOH) or International Standard Organisation under the ISO/IEC 17025 Testing and Calibration Laboratories, to carry out nanomaterials' detection analysis. The engagement with certified private laboratories is commonly practised within the FSQD's operation. For instance, the analytical food services for the issuance of health certificate for exportation, maleic acid analysis, nitrate analysis in bird's nest and analysis for ceramic wear, are offered by private laboratories and other agencies certified by MOH (Food Safety and Quality Division n.d.). The research centre runs by the public, and private universities may also provide such service consequently expand the research interest in nanotechnology industrial process such as the food industry. Malaysia has a well-structured institutional framework for the implementation of mandatory labelling requirement, particularly for research infrastructure and laboratory facility.

However, the enforcement and monitoring activity for nanotechnology food probably going to be difficult. Food products in Malaysia are not subjected to pre-market approval. Therefore, it is challenging to ensure labelling compliance by food manufacturers or distributors, especially for imported food products. Even with persistent surveillance activity from the enforcement agency, it would be difficult to distinguish between nanofood and conventional food, unless the product is submitted to the laboratory for detection analysis. If nanofood is subjected to pre-market approval, the regulatory authority can closely monitor the compliance among manufacturers or importers. For example, the labelling of genetically modified (GM) food that is subjected to pre-market approval as required by the Biosafety Act 2007 [Act 678]. Section 11 of the Biosafety Act requires any form of release activities including putting into the market any GMs product is subjected to approval for National Biosafety Board. Hence, the enforcement authority would have a record of the product derived from GM and make a necessary inspection on the approved products.

Following the practice of GMOs labelling, the implementation of nanofood labelling would be systemise if there is an institution to monitor the applications of nanotechnology in the agricultural and food industry, particularly among the local food manufacturers. The present nanotechnology research centres may undertake monitoring responsibility. It does not only allow the centre to gather data of product with ENMs but also open new research opportunities on nanomaterials in this industry. 
Besides that, to ensure the success of mandatory labelling, it requires strong cooperation and commitment from food manufacturers and distributors to honestly disclose that their food product is a nanofood. The guideline for labelling of nanofood must be made available to the food manufactures, food distributors, and consumers to streamline the labelling requirement, in addition to the requirement in the legislation.

It is ideal if there is close cooperation between the enforcement agency and the consumers' associations to monitor the compliance among food manufacturers and distributors. As mentioned earlier, France consumers associations UFC-Que Choisir actively involved in monitoring the nanotechnology labelling compliance. It is the association that filed the complaint to the court against Mars, Casino, McCormick and Jacobs Douwe Egberts for failure to placed nano label on their products (Michail, 2018).

Furthermore, it is also important to ensure that the labelling requirement does not lead to the negative stigma or nano "phobia". The applications of nanotechnology are extended to various industries such as medicine, environmental protection, engineering and not all imposed safety and health risk. For that matter, the enforcement agency should have educational or awareness programs to the members of the society. Such program is to explain on the nature of nanotechnology, benefits from engaging with the technology, concern about nanofood, enlighten the public about nanofood labelling and explain the labelling objective. Society needs to be acquainted with nanofood and be informed with their food choice. The label is not to frighten consumers or to prohibit consumers from consuming nanofood but to enable informed choices.

\section{Conclusion}

The commercial benefit or promise of nanotechnology in food and agricultural industry is beyond doubt, but the promising technology is now turned into a controversial technology when scientific studies suggesting that ENMs in food products could pose safety and health risks. Nanotechnology is, in fact, a double edge sword. For that matter, nanotechnology in this industry within the next few years present a unique window of opportunity to create a necessary regulatory framework to secure responsible development of nanotechnology that does not discard the nature of risks connected with ENMs. Mandatory labelling is one of the necessary regulatory action, to informed consumers about the status of food products. However, the implementation is challenging due to scientific uncertainties surrounded the tiny particles, absence of a harmonised definition, detection of nanomaterials in a final product, and complexity in implementation and enforcement. It establishes that the mandatory nanofood labelling could be implemented within Malaysia food regulatory framework. The labelling requirement should be narrowed only to engineered nanomaterials (ENMs), and the precautionary principle is adopted as a legal justification for mandatory labelling even though the scientific risks are either uncertain, incomplete or even unavailable. There is also an urgent need to clarify the legal definition of ENMs within the Malaysian food industry. Besides that, there are various detection methods available to identify and characterise ENMs in the final product and the food authority must identify the appropriate techniques to detect, measure, and characterize diverse ENMs in food matrices. It is also necessary to strengthen the enforcement institutions and tighten the cooperation with food manufacturers, distributors and consumers associations. Importantly, this study hopes to significantly contribute to improving the legal provisions on food information system for a product of emerging technology such as nanofood by pushing forward the legal requirement for nanofood labelling.

\section{Acknowledgements}

This research is financially supported by the Ministry of Education under the research grant no. FRGS/1/2019/SSI10/UITM/03/1.

\section{References}

Aschberger, K., Rauscher, H., Crutzen, H., Rasmussen, K., Christensen, F. M., Sokull-Klüttgen, B., \& Stamm, H. (2014). Considerations on information needs for nanomaterials in consumer products. European Commission Joint Research Centre Institute for Health and Consumer Protection, Brussels.

Asia Nano Forum. (2018). Asia Nano Forum Annual Report 2018 (V. 20181215). Retrieved from https://www.asia-anf.org/wp-content/uploads/2018/12/AnnualReport2018_1215_Final.pdf

Brownsword, R., \& Goodwin, M. (2012). Law and the Technologies of the Twenty-first Century: Text and Materials. Cambridge University Press. https://doi.org/10.1017/cbo9781139047609

Chuah, A. S., Leong, A. D., Cummings, C. L., \& Ho, S. S. (2018). Label it or ban it? Public perceptions of nano-food labels and propositions for banning nano-food applications. Journal of Nanoparticle Research, 20(2), 36. https://doi.org/10.1007/s11051-018-4126-5 
Contado, C. (2015). Nanomaterials in consumer products: A challenging analytical problem. Frontiers in Chemistry, 3, 48-67. https://doi.org/10.3389/fchem.2015.00048

Dana, D. A. (2012). Toward Risk-Based, Adaptive Regulatory Definitions in The Nanotechnology Challenge: Creating Legal Institutions for Uncertain Risk. Cambridge University Press. https://doi.org/10.1017/cbo9780511988554.008

EFSA Panel on Food Additives and Nutrient Sources added to Food (ANS), Younes, M., Aggett, P., Aguilar, F., Crebelli, R., Dusemund, B., ... \& Gundert-Remy, U. (2018). Re - evaluation of silicon dioxide (E 551) as a food additive. EFSA Journal, 16(1). https://doi.org/10.2903/j.efsa.2018.5088

EFSA Scientific Committee. (2011). Guidance on the risk assessment of the application of nanoscience and nanotechnologies in the food and feed chain. EFSA Journal, 9(5), 2140. https://doi.org/10.2903/j.efsa.2011.2140

European Commission. (n.d). Nanoparticles in food: Analytical methods for detection and characterisation. Retrieved from https://cordis.europa.eu/project/rcn/93181/factsheet/en

Food and Drug Administration. (2007). Nanotechnology task force report. Rockville, Maryland: Food and Drug Administration.

Food Safety and Quality Division. (2004). Food Safety Legislation Science and Risk-Based Approaches to Harmonisation: Food Safety Legislation in Malaysia. FAO/WHO Regional Conference on Food Safety for Asia and the Pacific, Seremban, Malaysia. Retrieved from http://www.fao.org/3/ad698e/ad698e.htm

Food Safety and Quality Division. (n.d). Analytical services of private laboratories and other agencies. Retrieved from http://fsq.moh.gov.my/v6/xs/page.php?id=441000592

Friends of the Earth. (2014). Tiny Ingredients Big Risks: Nanomaterials Rapidly Entering Food and Farming. United States: Author.

Gray, K. A. (2011). Five Myths about Nanotechnology in the Current Public Policy Debate: A science and engineering perspective: Creating Legal Institutions for Uncertain Risks. In The Nanotechnology Challenge: Creating Legal Institutions for Uncertain Risks (pp. 11-60). Cambridge Press. https://doi.org/10.1017/cbo9780511988554.003

Hamdan, H. (2014). NanoMalaysia Programme (2011-2020): engine of growth for innovative Malaysia. Journal of Experimental Nanoscience, 9, 2-8. https://doi.org/10.1080/17458080.2013.822109

Hansson, S. O. (2018). The Precautionary Principle. Handbook of Safety Principles, 258-283. https://doi.org/10.1002/9781119443070.ch12

Intergovernmental Forum on Chemical Safety. (2008). Summary of the sixth session of the intergovernmental forum on chemical safety. Dakar, Senegal. Retrieved from https://enb.iisd.org/vol15/enb15160e.html

International Standard Organisation. (2005). ISO/TC 299: Nanotechnologies. Retrieved from https://www.iso.org/committee/381983.html

International Standard Organization. (2019). Nanotechnologies - Plain language explanation of selected terms from the ISO/IEC 80004 series. Retrieved from https://www.iso.org/obp/ui/\#iso:std:iso:tr:18401:ed-1:v1:en

Ismail, S., Budin, S., \& Ali, S. A. M. (2019). The nanotechnology application and workforce health and safety-a study of the Malaysia laws, statutory regulations and guidelines on nanotechnology. Journal of Physics: Conference Series, 1349(1), 012031. IOP Publishing. https://doi.org/10.1088/1742-6596/1349/1/012031

Karim, E., \& Munir, A. B. (2015). Nanotechnology: Sketching the next big thing in Malaysian context. Nanotech. L. \& Bus., 12, 161.

King, T., Osmond-McLeod, M. J., \& Duffy, L. L. (2018). Nanotechnology in the food sector and potential applications for the poultry industry. Trends in Food Science \& Technology, 72, 62-73. https://doi.org/10.1016/j.tifs.2017.11.015

Klinke, A., \& Renn, O. (2002). A New Approach to Risk Evaluation and Management: Risk - Based, Precaution - Based, and Discourse - Based Strategies1. Risk Analysis, 22(6), 1071-1094. https://doi.org/10.1111/1539-6924.00274

Letchumi Thannimalay. (2013). Nanotechnology Safety and Risk Governance in Malaysia. Paper presented at the Nano Malaysia, Convention and Expo, Malacca, Malaysia.

Martirosyan, A., \& Schneider, Y. J. (2014). Engineered nanomaterials in food: implications for food safety and 
consumer health. International Journal of Environmental Research and Public Health, 11(6), 5720-5750. https://doi.org/10.3390/ijerph110605720

Michail, N. (2017). Unlabelled nanomaterials found in French food samples. Retrieved from https://www.foodnavigator.com/Article/2017/11/16/Unlabelled-nanomaterials-found-in-French-food-sampl es

Michail, N. (2018). Four manufacturers face Paris High Court legal complaint over undeclared nanoparticles. Retrieved from https://www.foodnavigator.com/Article/2018/01/23/Four-manufacturers-face-Paris-High-Court-legal-compl aint-over-undeclared-nanoparticles

Moses, L. B. (2013). How to think about law, regulation and technology: Problems with 'technology'as a regulatory target. Law, Innovation and Technology, 5(1), 1-20. https://doi.org/10.5235/17579961.5.1.1

Reins, L. (2019). Regulating New Technologies in Uncertain Times - Challenges and Opportunities. In Regulating New Technologies in Uncertain Times (pp. 19-28). TMC Asser Press, The Hague. https://doi.org/10.1007/978-94-6265-279-8_2

Roca, J. B., Vaishnav, P., Morgan, M. G., Mendonça, J., \& Fuchs, E. (2017). When risks cannot be seen: Regulating uncertainty in emerging technologies. Research Policy, 46(7), 1215-1233. https://doi.org/10.1016/j.respol.2017.05.010

Rogers, M. A. (2016) Naturally occurring nanoparticles in food. Current Opinion in Food Science, 7, 14-19. https://doi.org/10.1016/j.cofs.2015.08.005

Rothstein, H., Irving, P., Walden, T., \& Yearsley, R. (2006). The risks of risk-based regulation: Insights from the environmental policy domain. Environment International, 32(8), 1056-1065. https://doi.org/10.1016/j.envint.2006.06.008

Sachs, N. M. (2011). Rescuing the strong precautionary principle from its critics. U. Ill. L. Rev., 1285-1338. https://doi.org/10.31228/osf.io/4xgv8

Salvi, L. (2015). The EU's Soft Reaction to Nanotechnology Regulation in the Food Sector. Eur. Food \& Feed L. Rev., 10, 186.

Schwirn, K., Tietjen, L., \& Beer, I. (2014). Why are nanomaterials different and how can they be appropriately regulated under REACH? Environmental Sciences Europe, 26(1), 1-9. https://doi.org/10.1186/2190-4715-26-4

Singh, G., Stephan, C., Westerhoff, P., Carlander, D., \& Duncan, T. V. (2014). Measurement Methods to Detect, Characterize, and Quantify Engineered Nanomaterials in Foods. Comprehensive Reviews in Food Science and Food Safety, 13, 693-704. https://doi.org/10.1111/1541-4337.12078

Snir, R. (2014). Trends in global nanotechnology regulation: the public-private interplay. Vand. J. Ent. \& Tech. L., 17, 107-140. Retrieved from http://www.jetlaw.org/wp-content/uploads/2015/03/Snir_Final.pdf

Stokes, E. (2012). Nanotechnology and the products of inherited regulation. Journal of law and society, 39 , 93-112. https://doi.org/10.1111/j.1467-6478.2012.00572.x

Todt, O., \& Luján, J. L. (2014). Analyzing Precautionary Regulation: Do Precaution, Science, and Innovation Go Together? Risk Analysis, 34(12), 2163-2173. https://doi.org/10.1111/risa.12246

\section{Copyrights}

Copyright for this article is retained by the author(s), with first publication rights granted to the journal.

This is an open-access article distributed under the terms and conditions of the Creative Commons Attribution license (http://creativecommons.org/licenses/by/4.0/). 